\title{
UMA CONCISA PROSOPOGRAFIA DOS CONSELHEIROS DO CONSELHO DE ADMINISTRAÇÃO (CAD) DA COMPANHIA DE SANEAMENTO DO PARANÁ (SANEPAR) \\ ENTRE 2003 E 2010
}

\author{
Marcus Roberto de Oliveira ${ }^{1}$
}

\begin{abstract}
Resumo: Com a posse de Roberto Requião no governo do Estado do Paraná em 2003, um expressivo conflito político é iniciado no campo do saneamento básico (água tratada e esgotamento sanitário) paranaense. Amparado num acordo de acionistas formalizado em dezembro de 1998 pelo governo Jaime Lerner (antecessor de Requião) acerca do controle da Companhia de Saneamento do Paraná (SANEPAR), o conglomerado do Dominó Holdings passou a desfrutar de significativa influência nas decisões da SANEPAR e, consequentemente nas iniciativas de formulação, implantação e administração dos serviços de abastecimento de água e coleta de esgoto na região. $\mathrm{O}$ embate envolvendo o governo Requião e a Dominó Holdings fundamentou-se na divergência de visões políticoadministrativas que de um lado opunha uma socialização estratégica de tais ofícios e, do outro, sua exploração especulativa financeira. Nessa dicotomia, por meio de um enfrentamento que envolveu agentes estatais e privados, o controle das políticas públicas de saneamento básico foi objeto de disputa, num panorama que perdurou de janeiro de 2003 a dezembro de 2010. Assim, o presente artigo tem como objetivo oferecer uma sucinta análise prosopográfica, a partir de capitais, posicionamentos e trajetórias, dos principais agentes dessa querela: os conselheiros do Conselho de Administração (CAd) da SANEPAR. O referido recorte tem como referências os lavrados poderes dessa estrutura nas definições dos serviços de água e esgoto do Paraná, bem como sua configuração em espaço de rezingas políticas no período mencionado.
\end{abstract}

Palavras-chave: Prosopografia, Conselheiros do CAd da SANEPAR entre 2003 e 2010, Capitais, Conflitos, Trajetórias.

\section{A CONCISE PROSOPOGRAPHY OF THE DIRECTORS OF THE BOARD OF DIRECTORS (CAD) OF THE COMPANHIA DE SANEAMENTO DO PARANÁ (SANEPAR) BETWEEN 2003 AND 2010}

\begin{abstract}
With Roberto Requião 's inauguration in Paraná state government in 2003, a significant political conflict is initiated in the field of sanitation (treated water and sanitary sewage) in Paraná State. Backed by a shareholders' agreement formalized in December 1998 by the Jaime Lerner (predecessor of Requião) government regarding the control of the Sanitation Company of Paraná (SANEPAR), the conglomerate of Dominó Holdings enjoyed significant influence in the decisions of SANEPAR and consequently in the initiatives of formulation, implementation and administration of water supply and sewage collection services in the region. The clash involving the government Requião and Dominó Holdings was based on the divergence of political-administrative visions that on one side opposed a strategic socialization of such offices and, on the other, its speculative financial exploration. In this dichotomy, by means of a confrontation involving state and private agents, the control of the public policies of basic sanitation was object of dispute, in a panorama that lasted from January of 2003 to December of 2010. Thus, the present article has as objective to offer a brief prosopographic analysis, from capitals, positions and trajectories, of the main agents of this quarrel: the directors of the Board of Directors (CAd) of SANEPAR. The referred clipping has as reference the plowed powers of this structure in the definitions of the
\end{abstract}

\footnotetext{
${ }^{1}$ Bacharel em Ciências Sociais, mestre em Sociologia Política e doutorando em Sociologia pela Universidade Federal do Paraná (UFPR). Pesquisador do Núcleo de Estudos Paranaenses da UFPR (NEP-UFPR). Bolsista Coordenação de Aperfeiçoamento de Pessoal de Nível Superior (CAPES).

E-mail: mr_olivei@yahoo.com.br
} 
water and sewage services of Paraná, as well as its configuration in space of rezingas policies in the mentioned period.

Key words: Prosopography, Counselors of the CAd of SANEPAR between 2003 and 2010, Capitals, Conflicts, Trajectories.

Introdução - A SANEPAR e as disputas entre os setores estatal e privado no período 20032010

A SANEPAR, a companhia mista (que combina gestões estatais e privadas) responsável pelos serviços de abastecimento de água e coleta de esgoto (saneamento básico) no estado do Paraná foi fundada em 1963 “[...] com o objetivo de abrir novos horizontes no setor" (SANEPAR, 2013, não p.).

Sob o governo de Jaime Lerner (do antigo Partido da Frente Liberal - PFL), por meio da "Lei Estadual no. 11.963" de dezembro de 1997, o Estado do Paraná obteve a autorização para "alienar ações de sua propriedade no capital social" da SANEPAR, "desde que mantivesse o controle da companhia" (XAVIER, 2002, não p.). No entanto, o conservado controle estatal figurou de uma maneira contraditória naquela época, pois a regulamentação por parte do Estado era compreendida enquanto um entrave para uma almejada expansão da empresa junto ao mercado privado de ações (RIGOLON; GIAMBIAGI, 1999). Desse modo, em 4 de setembro de 1998, sob a presidência de Giovani Gionédis (então secretário estadual da Fazenda), a SANEPAR tomou iniciativas no intuito de fortalecer o setor privado da companhia: o conglomerado empresarial Dominó Holdings (ligado a interesses econômicos transnacionais) (BLOOMBERG, 2018, não p.). Enquanto braço privado da SANEPAR, a Dominó Holdings foi sistemática e conjunturalmente favorecida (XAVIER, 2002, não p.).

O pacto administrativo firmado concedeu poder ao setor privado da SANEPAR, mas as crises econômicas que se aprofundaram ao final da década de 1990 (FILGUEIRAS, 2000) formaram expressivos embaraços ao desempenho da SANEPAR no mercado financeiro. Nessa conjuntura, já em maio de 2002, a companhia adiou "a sua oferta global de ações preferências devido à deterioração das condições de mercado" (VALOR ONLINE, 2002 a, não p.). E no mês de julho do mesmo ano, a "agência de classificação de risco Moody's colocou sob observação, para rebaixamento", o crédito da SANEPAR junto à mercancia financeira, a "agência disse ter preocupação com a capacidade" da empresa "de executar seu planejamento estratégico, uma vez que o mercado financeiro do país" enfrentava relevantes turbulências (VALOR ONLINE, 2002, não p.). 
Revista NEP - Núcleo de Estudos Paranaenses, Curitiba, v.5, n.1, jun. 2019 Dossiê Partidos Políticos e Conexões Familiares

ISSN: 2447-5548

A partir de janeiro de 2003, após a eleição de Roberto Requião (do antigo Partido do Movimento Democrático Brasileiro - PMDB) para o governo do Estado do Paraná, o predomínio da Dominó Holdings junto à companhia passou a ser juridicamente contestado, sob o argumento de que tal ordenamento "[...] retirou do Estado o poder-dever de manter o controle da SANEPAR", transgredindo "[...] de modo flagrante os termos da Lei Estadual 11.963" (SANEPAR, 2003, não p.). O embate entre o governo Requião e a Dominó Holdings fundamentava-se nas indicações de conselheiros para o Conselho de Administração (CAd) da SANEPAR. Nesse processo, o Executivo paranaense teria incumbência de indicar 5 (cinco) dos 9 (nove) integrantes do CAd. Ao braço privado da companhia caberiam 3 (três) indicações e aos funcionários da empresa, a eleição de 1 (um) conselheiro, fechando assim a principal estrutura dirigente da SANEPAR (SANEPAR, 2012, p. 4-7). No entanto, para as mais importantes deliberações da SANEPAR era exigido um quórum qualificado de 7 (sete) conselheiros. Na prática, as iniciativas do Governo do Paraná dependiam "da concordância dos representantes" da Dominó Holdings, "desde contratos, pagamento de dividendos até a fixação das tarifas de água e esgoto" (SANEPAR, 2003, não p.) $)^{2}$.

A disputa entre o governo Requião e a Dominó Holdings seguiu cada vez mais acirrada. O Executivo paranaense reivindicava a exclusividade da figura do "governador" na formalização de acordos junto à companhia (o que já era previsto na lei estadual 11.963, de 1997), pois o pacto cerne da disputa foi oficializado pelo secretário da Fazendo do governo antecessor (SANEPAR, 2003, não p.).

Ocorreram intensas altercações na arena judicial. Em 13 de fevereiro de 2003, por meio do Decreto 452, o governo Requião declarou a ineficácia do acordo dos acionistas de 1998, classificando-o como uma iniciativa bilateral que proporcionou ao setor privado da companhia um poder de mando incompatível com sua participação acionária. Em contrapartida, no ano de 2004, a Dominó Holdings obteve uma liminar favorável ao acordo de acionistas firmado no governo Jaime Lerner. Mas "Requião revogou o decreto que anulava o acordo, de modo a eliminar o motivo da ação, e em setembro" de 2004, a 2. "Vara da Fazenda Pública de Curitiba

\footnotetext{
2 A mesma lógica se estendia para a composição da Diretoria Executiva, onde os "Diretores indicados pelo acionista minoritário detinham o comando real da Companhia". Cabia a Dominó Holdings definir, "ante os termos do acordo de acionistas, [...] os Diretores Superintendente (hoje denominado Diretor-Presidente), de Operações e Financeiro". Assim, "a gestão da Companhia" foi orientada por um plano de negócio e por um orçamento anual, "ambos elaborados por 3 (três) diretores, a saber, o Diretor de Operações (indicado pela DOMINÓ), o Diretor Financeiro (idem) e o Diretor Administrativo (este indicado pelo ESTADO DO PARANÁ)" (SANEPAR, 2003, não p.).
} 
outorgou liminar dependurando novamente o pacto de acionistas (CASTRO, 2004, não p.), sendo esse anulado em 2005 pela Assembleia Legislativa do Paraná (TRIBUNA DO PARANÁ, 2005, não p.).

Com a reeleição de Requião em 2006 (FOLHA ONLINE, 2006, não p.), o embate Governo do Estado X Dominó Holdings prosseguiu firme. Em 2007, suspeitas de corrupção num contrato da companhia com a empreiteira Pavibrás abalou a hegemonia do Governo na gestão da SANEPAR. Tal situação frustrou a tentativa de anular "o leilão de venda de $39,71 \%$ das ações” da empresa à Dominó Holdings em 1998 (BASILE, 2007, não p.), gerando desentendimentos entre integrantes governistas na cúpula sanepariana (CAMPANA, 2007, não p.) e a suspensão do decreto legislativo que anulou o acordo de acionistas em 2005 (SANTOS, 2007, não p.).

Entre os anos de 2008 e 2010, a tensão entre os setores estatal e privado da SANEPAR intensificou-se ainda mais, a ponto do governador Requião asseverar a devolução de $\mathrm{R} \$ 744$ milhões investidos na companhia pela administração estadual por meio de empréstimos internacionais e a criação de uma nova estatal para os serviços de saneamento básico no Paraná (PAULA, 2009, não p.). No entanto, as referidas tentativas foram barradas pelo Supremo Tribunal de Justiça (STJ) (CASTRO, 2009, não p.), consolidando a estagnação do setor no Paraná (LAGINSKI, 2009, não p.) e um desgaste político que contribuiu para o retorno da oposição ao Executivo estadual após as eleições de 2010 com a vitória nas urnas de Beto Richa, do Partido da Social Democracia Brasileira (PSDB) (BENDLIN, 2010, não p.).

Ao longo dos governos de Roberto Requião, a exploração financeira dos serviços de água e esgoto e a remuneração do setor privado da companhia (liderado pelo consórcio Dominó Holdings) comtemplaram significativamente uma polarização entre Estado e mercado. A lógica dessa contraposição estabelece a estrutura do Estado como viciada, incompetente e reduto da corrupção política; a raiz de "todos os males" da ineficiência administrativa. Por outro lado, o mercado, (virtuoso, moderno e justo) figura como uma espécie de redenção acerca dos "prejuízos" econômicos e morais do Estado (SOUZA, 2015). Tal referencial pode ser compreendido enquanto uma definição unilateral que camufla e naturaliza as contradições e mazelas das transações de mercado, legitimando uma ideologia do "livre mercado", que historicamente beneficia os agentes mais abastados economicamente que integram as classes dominantes tradicionais (OLIVEIRA, 2012), desde os tempos escravagistas (SOUZA, 2017). 
Revista NEP - Núcleo de Estudos Paranaenses, Curitiba, v.5, n.1, jun. 2019

Nas deliberações promovidas pela empresa, quando iniciativas de regulamentação eram almejadas pelo governo estadual, uma série de dispositivos jurídicos foi acionada para garantir a os interesses dos acionistas privados e vice-versa. Assim, uma estrutura da SANEPAR merece atenção: o seu CAd. Conforme o estatuto da empresa, tal departamento tem a função de aprovar, deliberar e retificar iniciativas que dizem respeito à sua atuação enquanto empresa mista (público-privada) nas diversas áreas organizacionais (políticas públicas, contratações, mercado de ações, empréstimos, financiamentos, etc.), bem como eleger os diretores da companhia (SANEPAR, 2012, p. 3-7).

\section{O CAd da SANEPAR: subcampos e agentes}

O CAd da SANEPAR é a estrutura definida pelos acionistas da companhia por meio de assembleia geral (SANEPAR, 2012, p. 3) que, do alto dos seus crivos burocráticos, avaliza as medidas da empresa e administra o universo dos conflitos que envolvem interesses políticos contextualmente hegemônicos (SANEPAR, 2012, p. 3-7).

Entre 2003 e 2010, o papel do CAd da SANEPAR foi decisivo nos processos que se sucederam no planejamento, na implantação, na execução e na exploração dos serviços paranaenses de água e esgoto, mediante funções inerentes ao que se entende por "campo de poder" (BOURDIEU, 1996), no caso, especificamente, um “campo de poder" que ordena um campo social Água-Esgoto (AE) nas políticas públicas de saneamento básico no Paraná daquela época.

O campo social AE no Paraná é compreendido "como um espaço onde são construídos saberes e desenvolvidas práticas em torno dos objetos que justificam sua existência", e simultaneamente "como espaços de disputas por tudo quanto o faz mover-se". Nesse raciocínio, os seus "subcampos devem ser entendidos como espaços disciplinares" que "funcionam reproduzindo, em microescala, a mesma dinâmica do campo" social AE (LOPES et al, 2013, p. $820)$.

Diante de tal panorama cabem as seguintes interrogações: quem são os agentes sociais que integraram o CAd da SANEPAR no referido período? Quais critérios definiram sua composição? Quais os subcampos do campo social AE que foram representados no CAd da 
SANEPAR? O presente texto buscará responder preliminarmente essas perguntas apresentando sistematicamente informações referentes às posições sociais de cada conselheiro do CAd da SANEPAR nos subcampos vigentes na época, bem como às suas respectivas formações escolares, trajetórias profissionais, composições familiares. Por meio desses levantamentos será possível identificar os capitais detidos pelos dirigentes estudados.

Os subcampos empresarial, jurídico, político e profissional vigoraram no campo social AE e foram representados no CAd da SANEPAR entre 2003 e 2010. Vistos separadamente, os subcampos empresarial, jurídico, político e profissional contam, respectivamente com $8 ; 14 ; 13$ e 5 conselheiros. A identificação dos subcampos acima foi calculada a partir do número total de conselheiros que assinaram os Relatórios Anuais de Administração e Demonstrações Contábeis da SANEPAR de 2003 a 2010. Tal opção é justificada pelos casos em que um conselheiro integra mais de um subcampo (é possível observar que dos 26 conselheiros pesquisados, 13 integravam mais de um subcampo entre 2003 e 2010; um percentual de 50\%) e pelo fato dos documentos citados materializarem decisões importantes da companhia.

\section{O subcampo empresarial do campo social AE no CAd da SANEPAR}

O subcampo empresarial do campo AE é um microcosmo fundamentado pelos interesses privados de empresas e organizações que os agentes envolvidos representam. As questões relacionadas aos financiamentos de obras, captação de recursos, mercado financeiro e, principalmente, a remuneração dos acionistas minoritários da SANEPAR, estiveram presentes na agenda do subcampo empresarial do campo social AE no CAd da SANEPAR entre 2003 e 2010. Seus componentes junto ao CAd foram: Caio Julio Cesar Brandão Pinto, JeanMarie D’asp, Júlio César de Souza Araújo Filho, Kevin Michael Altit, Marlik Bentabet, Renato Torres de Faria, Ricardo Coutinho de Senna e Rodrigo Bhering de Andrade.

As formações profissionais são capitais em qualquer campo ou subcampo, sendo que nessa perspectiva enquadram-se nas categorias cultural (pelos conhecimentos científicos que as permeiam) e social (pelo prestígio do acesso limitado de grande da população brasileira ao ensino superior) (THIRY-CHERQUES, 2006). No subcampo empresarial do campo AE no CAd da SANEPAR, a área tecnológica predomina nas formações profissionais verificadas. A 
partir das formações profissionais, também é possível identificar as instituições escolares de ensino superior que proporcionaram tais instruções aos conselheiros pesquisados. Dessa forma, as instituições escolares de ensino superior figuram de modo variado.

Juntamente com formações profissionais socialmente reconhecidas, a carreira profissional dos conselheiros do CAd da SANEPAR também forma um conjunto de informações importantes para a compreensão das iniciativas desses agentes e seus respectivos campos. Afinal, um currículo exemplar é um capital com significativo poder de conversão (SAINT-MARTIN, 1995), sobretudo no que diz respeito à ocupação de cargos de Estado (OLIVEIRA, 2012).

Alguns agentes do subcampo empresarial exerceram cargos de estado no Brasil e na França. As experiências em território francês deve-se ao fato de 2 conselheiros serem de nacionalidade francesa e no seu país disporem de capitais que possibilitaram acesso a cargos no Estado. Dos 6 (seis) restantes, todos brasileiros, 4 (quatro) ocuparam cargos de Estado no Brasil; um percentual de $66 \%$, o que corresponde a dois terços.

\section{O subcampo jurídico do campo social AE no CAd da SANEPAR (2003-2010)}

Representado por Altevir Rocha de Andrade, Caio Julio Cesar Brandão Pinto, Carlos Frederico Marés de Souza Filho, Heron Arzua, Izabel Cristina Marques, Jozélia Nogueira Broliani, Kevin Michael Altit, Luiz Fernando Ferreira Delazari, Marco Antonio Lima Berberi, Nestor Celso Imthon Bueno, Pedro Henrique Xavier, Rodrigo Bhering de Andrade, Rogério Distefano e Sergio Botto de Lacerda, o subcampo jurídico do campo social AE contou com o maior número de representantes no CAd da SANEPAR entre 2003 e 2010. Dos 26 conselheiros pesquisados, 14 integraram essa estrutura; um percentual de 54\% do total.

No subcampo jurídico do campo social AE no CAd da SANEPAR, os conhecimentos e trajetórias acerca dos complexos processos jurídicos são os capitais mais eficientes, mobilizando agentes sociais dos setores estatal e privado. Nesse espaço todos conselheiros possuem formação profissional em Direito. 
Revista NEP - Núcleo de Estudos Paranaenses, Curitiba, v.5, n.1, jun. 2019

Sobre as instituições escolares de ensino superior que fomentaram o subcampo jurídico predomina o setor de ciências jurídicas da Universidade Federal do Paraná (UFPR). A UFPR formou $57 \%$ dos conselheiros componentes do subcampo.

As carreiras de Estado dos conselheiros do subcampo jurídico também oferecem números interessantes. Todos os 14 conselheiros do subcampo jurídico já integraram o funcionalismo estatal. Nessa plena lotação, 8 conselheiros exerceram o cargo de Procurador de Estado, representando 57\% do total do subcampo, 6 o de conselheiro em outras instituições estatais ou mistas e 5 o de secretário de Estado. Tais percentuais revelam que o subcampo jurídico compartilhou conselheiros com o subcampo político do campo social AE, o que contempla o cenário de disputas que marcou o período 2003-2010.

\section{O subcampo político do campo social AE no CAd da SANEPAR (2003-2010)}

Os conselheiros Altevir Rocha de Andrade, Caio Julio Cesar Brandão Pinto, Carlos Frederico Marés de Souza Filho, Darcy Deitos, Heron Arzua, José Maria Ferreira, Jozélia Nogueira Broliani, Júlio César de Souza Araújo Filho, Luiz Fernando Ferreira Delazari, Marcos Vinícius Ferreira Mazoni, Nestor Celso Imthon Bueno, Pedro Henrique Xavier e Tatiana Cruz Bove Iatauro foram os representantes do subcampo político do campo social AE no CAd da SANEPAR entre 2003 e 2010.

O subcampo político do campo social $\mathrm{AE}$ é um microcosmo ligado diretamente às decisões do Governo do Estado do Paraná, visto que o controle administrativo da SANEPAR é garantido ao governo estadual conforme legislação vigente. Nessa perspectiva, o subcampo político gerencia e materializa a regulamentação instituída junto ao setor de saneamento básico no estado.

Entre 2003 e 2010, a formação jurídica dos referidos conselheiros se destaca. Dos 13 conselheiros que integram tal subcampo, 8 são formados em Direito, proporcionando um percentual de $62 \%$ do total dos componentes. O rol de especialidades do subcampo político do campo social $\mathrm{AE}$ foi fomentado por um significativo número de instituições escolares de ensino superior. A UFPR foi responsável pela formação profissional de $38 \%$ dos conselheiros do subcampo político do campo social AE. 
Revista NEP - Núcleo de Estudos Paranaenses, Curitiba, v.5, n.1, jun. 2019

Em termos de exercício de cargos de Estado, o subcampo político do campo social AE proporciona uma variedade interessante no período pesquisado. Assim como no subcampo jurídico do campo social AE, no subcampo político, todos os conselheiros também já exerceram cargos de Estado. Diante desse cenário, dos 13 que integram o subcampo, 54\% exerceram cargos no funcionalismo de nível estadual. Além disso, 6 já ocuparam pastas de secretário de Estado (percentual de 46\% do total), 2 já foram procuradores de Estado (15\%) e 1 foi promotor de justiça (8\%). Tais índices revelam a proximidade entre os subcampos jurídico e político.

\section{O subcampo profissional do campo social AE no CAd da SANEPAR (2003-2010)}

Representado pelos conselheiros Hamilton Aparecido Gimenez, Iwan Sabatella Filho, Júlio César da Silva, Marcos Vinícius Ferreira Mazoni e Tatiana Cruz Bove Iatauro, o subcampo profissional do campo social AE foi o espaço com menos integrantes no CAd da SANEPAR entre 2003 e 2010. Tal estrutura contemplou atividades burocráticas da SANEPAR nos serviços de água e esgoto. Nesse subcampo encontra-se o conselheiro eleito pelos funcionários da SANEPAR; garantido pelas diretrizes estatutárias da companhia (SANEPAR, 2012, p. 4).

No subcampo profissional do campo social AE no CAd da SANEPAR foram registradas formações profissionais em administração de empresas, pedagogia, ciências contábeis, processamento de dados e engenharia mecânica. Acerca das instituições escolares de ensino superior proporcionaram tais diplomas, a Fundação Getúlio Vargas (FGV) formou 2 dos 5 conselheiros que integram o subcampo, um percentual de $40 \%$ do total de componentes.

Sobre os cargos de Estado ocupados pelos conselheiros do subcampo profissional do campo social AE (2003-2010), as esferas municipal, estadual e federal foram contempladas. Os ofícios técnico-administrativos do funcionalismo público estadual predominaram no subcampo profissional do campo social AE. Dos 5 conselheiros integrantes, 4 assumiram cargos dessa natureza; um percentual de $80 \%$ do total do subcampo.

\section{O capital político familiar no CAd da SANEPAR (2003-2010)}


Além dos capitais referentes às formações e trajetórias profissionais também é possível assinalar outro tipo de capital nos subcampos do campo social AE que pode ser compreendido como uma espécie de alicerce dos demais recursos mobilizadores, trata-se do capital políticofamiliar (MONTEIRO, 2016).

Por meio de tal raciocínio, “[...] a família enquanto uma palavra de ordem, uma categoria, princípio coletivo de construção da realidade coletiva, uma ficção bem fundamentada" (MONTEIRO, 2016, p. 562), exerce uma significativa função de reprodução no que tange os posicionamentos de seus membros numa dada realidade social e, consequentemente, no acúmulo de capitais culturais, econômicos e sociais por parte dos familiares. Assim:

O grupo familiar existe enquanto criação social que é capaz de reproduzir estruturas existentes. Os interesses dos grupos familiares são múltiplos. Numa ordem societária capitalista, a ampliação do capital econômico se torna um dos interesses centrais. E o capital político familiar é um desses capitais que se converte em capital econômico. É a esfera da política um dos espaços em que a família torna-se estratégica no sentido de ampliação dos capitais (MONTEIRO, 2016, p. 562).

É importante ressaltar que os vínculos que proporcionam acúmulo, reprodução e conversão de capitais político-familiares vão além dos laços consanguíneos. Nessa lógica, o conceito de "parentela" expressa presenças de agregados, amigos e apadrinhados, consolidando um conjunto de partidários de famílias políticas, ou seja, uma "rede política entrelaçada que assegura os interesses e garante a sustentação da oligarquia" (LEWIN, 1993, p. 10). Esses alinhamentos desnudam os privilégios que essas famílias ostentam, em especial “[...] a possibilidade de obterem altos salários que podem ser somados ao capital obtido na forma de lucros, dividendo, juros, aluguéis e outras rendas do capital”, os quais são “[...] conquistados, quase sempre, pelo acesso que lhes são permitidos ao Estado pelo capital-político familiar e pelo expressivo volume de capital econômico" (MONTEIRO, 2016, p. 573).

O capital político-familiar está presente em todos os subcampos do campo social AE no CAd da SANEPAR do período 2003-2010. Nessa averiguação os subcampos jurídico, político e profissional merecem destaque. Tais estruturas respectivamente alcançam percentuais de $50 \%, 69 \%$ e $40 \%$ do total de conselheiros que integram cada subcampo. Nesse cenário, ao 
especificar os conselheiros que possuem parentes que exercem ou já exerceram cargos no Estado, os percentuais são $71 \%, 85 \%$ e $40 \%{ }^{3}$.

\section{Considerações finais}

Preliminarmente, é plausível compreender que os serviços de saneamento básico no estado do Paraná entre 2003-2010 (período correspondente aos governos estaduais de Roberto Requião) proporcionaram a vigência do campo social $\mathrm{AE}$, na medida em que uma diversidade de agentes sociais atuou num conjunto de consensos e conflitos que revelam seus respectivos subcampos e capitais mobilizados junto à institucionalização dos ofícios em questão.

Em tais processos, a SANEPAR pode ser compreendida como a expressão do campo poder no campo $\mathrm{AE}$, em especial na atuação (e composição) do CAd da companhia, visto que essa ordenação deliberou as demandas do setor de saneamento básico na época. Nesse raciocínio, a identificação dos capitais referentes aos agentes sociais enredados oferece significativos subsídios no que diz respeito à compreensão da elaborada dicotomia "Estado $\mathrm{X}$ mercado" que vigorou sistematicamente no período em apreço.

Quando os capitais são depreendidos como recursos mobilizadores num contexto de disputas, os subcampos do campo social AE no CAd da SANEPAR sugerem interesses e posturas classistas variadas. Nessa ótica, os subcampos empresarial, jurídico, político e profissional engendraram a dinâmica dos embates na época. Assim, é plausível sustentar que os critérios que fundamentam tais espaços no CAd da SANEPAR remetem aos capitais identificados.

As formações escolares e as trajetórias profissionais dos conselheiros pesquisados se configuram em capitais culturais e sociais. Tais pecúlios evidenciam movimentos de conversão e reconversão acerca de capitais econômicos; pois uma reconhecida educação e um bem sucedido currículo requerem investimentos materiais e almejados retornos por parte dos agentes sociais implicados.

Visto que no período 2003-2010 prevaleceram conflitos que demandavam soluções jurídicas, políticas e técnicas, a maneira como as formações escolares e as trajetórias

\footnotetext{
3 Tais percentuais têm como referência um conjunto de informações oriundas de matérias de imprensa e documentações disponíveis na web.
} 
profissionais encontraram-se distribuídas nos subcampos em questão mostra que tais capitais foram pré-requisitos para a defesa dos interesses arbitrados e pautados no campo de poder.

Outro tipo de capital também foi imprescindível nas conflagrações do período em pauta: o capital político-familiar. Presente em todos os subcampos do campo social AE que constituíram o CAd da SANEPAR entre 2003 e 2010, o capital político familiar pode ser igualmente vislumbrado como um vultoso elemento de conversão e reconversão acerca dos demais tipos de capital sondados. Tanto que, conforme as fontes disponíveis, nos subcampos do campo social AE que mais se destacaram nas altercações verificadas (especificamente, os subcampos jurídico e político) foi possível averiguar apreciáveis percentuais de incidência de capital político-familiar nessas estruturas.

\section{Referências}

BASILE, J. Decisão do STJ impede reestatização da SANEPAR. São Paulo, 2007. Disponível em: <http://g1.globo.com/Noticias/Economia_Negocios/0, AA16417639356,00.html>. Acesso em: 17 mar. 2018.

BENDLIN, A. C. (2010). Ex-prefeito de Curitiba, Beto Richa (PSDB) é o novo governador do Paraná. Curitiba, 2010. Disponível em: $<$ https://eleicoes.uol.com.br/2010/parana/ultimas-noticias/2010/10/03/ex-prefeito-de-curitibabeto-richa-psdb-e-o-novo-governador-do-parana.jhtm>. Acesso em: 29 mar. 2018. BLOOMBERG. Company Overview of Dominó Holdings S.A. Nova York, 2018. Disponível em:

<https://www.bloomberg.com/research/stocks/private/snapshot.asp?privcapId=41541797>. Acesso em: 29 mar.2018.

BOURDIEU, P. Razões práticas: sobre a teoria da ação. Campinas: Papirus, 1996.

CAMPANA, F. Tudo o que Requião não quer que você saiba sobre o escândalo na Sanepar. Curitiba, 2007. Disponível em: <http://www.fabiocampana.com.br/2007/06/tudo-oque-requiao-nao-quer-que-voce-saiba-sobre-o-escandalo-na-sanepar/>. Acesso em: 17 mar. 2018.

CAMPOS, P. H. P. Estranhas Catedrais: as empreiteiras brasileiras e a ditadura civil-militar, 1964-1988. Rio de Janeiro: EDUFF, 2014.

CASTRO, E. Decreto anula pacto de acionistas da Sanepar. Curitiba, 2004. Disponível em: <http://www.tribunapr.com.br/noticias/politica/decreto-anula-pacto-de-acionistas-dasanepar/>. Acesso em: 29 mar. 2018.

CASTRO, E. STJ anula medidas adotadas por Requião na Sanepar. Curitiba, 2004. Disponível em: <http://www.fabiocampana.com.br/2009/10/stj-anula-medidas-adotadas-pelogoverno-na-sanepar/>. Acesso em: 23 mar. 2018. 
Revista NEP - Núcleo de Estudos Paranaenses, Curitiba, v.5, n.1, jun. 2019

COMPANHIA DE SANEAMENTO DO PARANÁ - SANEPAR. Sem medo de defender o interesse público. Curitiba, 2003. Disponível em:

<http://www.sanepar.com.br/sanepar/calandrakbx/filesmng.nsf/48E08D0BEF31E0B9832570 36006BD6AF/\$File/COMUNICADO090704.pdf?OpenElement>. Acesso em: 15 mar. 2018.

COMPANHIA DE SANEAMENTO DO PARANÁ - SANEPAR. Estatuto social consolidado. Curitiba, 2012. Disponível em:

<http://site.sanepar.com.br/sites/site.sanepar.com.br/files/perfil_investidores_2012/estatuto_s ocial_24052016.pdf>. Acesso em: 15 mar. 2018.

COMPANHIA DE SANEAMENTO DO PARANÁ - SANEPAR. Meio século de saneamento no Paraná. Curitiba, 2013. Disponível em:

〈http://site.sanepar.com.br/noticias/meio-seculo-de-historia-do-saneamento-no-parana $>$.

Acesso em: 15 mar. 2018.

COMISSÃO DE VALORES MOBILIÁRIOS - CVM. Serviço Público Federal / Comissão de Valores Mobiliários (CVM) / Informações Anuais (IAN) 2003 - Sanepar. Brasília: [s/ed], 2003 a.

COMISSÃO DE VALORES MOBILIÁRIOS - CVM. Serviço Público Federal - Comissão de Valores Mobiliários (CVM) - Informações Anuais (IAN) 2004 - Sanepar. Brasília: [s/ed], 2004.

COMISSÃO DE VALORES MOBILIÁRIOS - CVM. Serviço Público Federal - Comissão de Valores Mobiliários (CVM) - Informações Anuais (IAN) 2005 - Sanepar. Brasília: [s/ed], 2005.

COMISSÃO DE VALORES MOBILIÁRIOS - CVM. Serviço Público Federal - Comissão de Valores Mobiliários (CVM) - Informações Anuais (IAN) 2006 - Sanepar. Brasília: [s/ed], 2006.

COMISSÃO DE VALORES MOBILIÁRIOS - CVM. Serviço Público Federal - Comissão de Valores Mobiliários (CVM) - Informações Anuais (IAN) 2007 - Sanepar. Brasília: [s/ed], 2007.

COMISSÃO DE VALORES MOBILIÁRIOS - CVM. Serviço Público Federal / Comissão de Valores Mobiliários (CVM) / Informações Anuais (IAN) 2008 - Sanepar. Brasília: [s/ed], 2008.

FILGUEIRAS, L. História do Plano Real - Fundamentos, impactos e contradições. São Paulo: Boitempo Editorial, 2000.

FOLHA ONLINE. Roberto Requião segue no governo do Paraná; veja perfil. São Paulo, 2006. Disponível em <http://www1.folha.uol.com.br/folha/brasil/ult96u86084.shtml >. Acesso em: 23 mar. 2018. 
Revista NEP - Núcleo de Estudos Paranaenses, Curitiba, v.5, n.1, jun. 2019 Dossiê Partidos Políticos e Conexões Familiares

ISSN: 2447-5548

HOCHMAN, G. A era do saneamento: as bases da política de saúde pública no Brasil. São Paulo: Hucitec/Anpocs, 1998.

LAGINSKI, F. (2009). Saneamento básico está estagnado. Curitiba, 2009. Disponível em: <http://www.tribunapr.com.br/noticias/parana/saneamento-basico-esta-estagnado/>. Acesso em: 29 mar. 2018.

LEWIN, L. Política e parentela na Paraíba: um estudo de caso da oligarquia de base familiar. Rio de Janeiro: Record, 1993.

LOPES, M. E. L.; SOBRINHO, M. D.; COSTA, S. F. G. "Contribuições da sociologia de Bourdieu para o estudo do subcampo da enfermagem". Texto \& Contexto Enfermagem, Florianópolis, 2013, vol.22, n.3, pp.819-825.

MATOS, H. Capital social e comunicação: interfaces e articulações. São Paulo: Summus, 2009.

MONTEIRO, J. M. "Parentesco e representação política: a força do capital político familiar na 54 legislatura no Congresso Nacional”. Revista NEP, Curitiba, 2016, v.2, nº 2, mai, p. 561-579.

OLIVEIRA, R. C. Na teia do nepotismo - Sociologia política das relações de parentesco e poder político no Paraná e no Brasil. Curitiba: Insight, 2012.

OLIVEIRA, M. R.; BORDIN, M. “O Campo Social 'Água e Esgoto': indicadores sobre a experiência brasileira”. Geographia Opportuno Tempore, Londrina, 2016, v. 2, n. 3, p. 7586.

PAULA, J. Requião quer fechar a Sanepar e abrir estatal para o setor. Paranavaí, 2009. Disponível em: <http://joaquimdepaula.com.br/index.php/2009/07/requiao-quer-fechar-asanepar-e-abrir-estatal-para-o-setor/>. Acesso em: 23 mar. 2018.

PEREIRA, F. M. "Classes sociais e hereditariedade: fundamentos sociológicos". In: OLIVEIRA, R. C. (org). Família importa e explica: Instituições políticas e parentesco no Brasil. Curitiba: Liber Ars, 2018.

RIGOLON, F.; GIAMBIAGI, F. “A Renegociação das Dívidas e o Regime Fiscal dos Estados". In: GIAMBIAGI, F.; MOREIRA, M. M (orgs). A economia brasileira nos anos 90. Rio de Janeiro: BNDES, 1999.

SAINT-MARTIN, M. "Reconversões e reestruturações das elites: o caso da aristocracia francesa”. Análise Social, Lisboa, 1995, vol xxx, n 134, p. 1023-1039.

SANTOS, I. Requião perde mais uma na briga com o Dominó. Curitiba, 2007. Disponível em: $<$ http://www.bemparana.com.br/noticia/47432/requiao-perde-mais-uma-na-briga-com-odomino >. Acesso em: 17 mar. 2018.

SCHUSTER, Z. L. L. Sanepar ano30: resgate da memória do saneamento básico do Paraná. Curitiba: Logos Press, 1994. 
Revista NEP - Núcleo de Estudos Paranaenses, Curitiba, v.5, n.1, jun. 2019

SOUZA, J. A tolice da inteligência brasileira - ou como o país se deixa manipular pela elite. São Paulo: LeYa, 2015.

SOUZA, J. A elite do atraso: da escravidão à Lava Jato. Rio de Janeiro: Leya, 2017. THIRY-CHERQUES, H. R. "Pierre Bourdieu: a teoria na prática". Rev. Adm. Pública, Rio de Janeiro, 2006, vol.40, n.1, pp.27-53.

TRIBUNA DO PARANÁ. AL aprova, por unanimidade, fim do pacto de acionistas da Sanepar. Curitiba, 2005. Disponível em: <http://www.tribunapr.com.br/noticias/al-aprovapor-unanimidade-fim-do-pacto-de-acionistas-da-sanepar/>. Acesso em: 29 mar. 2018.

VALOR ONLINE. Moody's coloca em observação ratings da Copel, CEB, Sanepar e Cemig. São Paulo, 2002. Disponível em $<$ http://www.valor.com.br/arquivo/300451/moody\%C2\%B4s-coloca-em-observacao-ratingsda-copel-ceb-sanepar-e-cemig >. Acesso em: 29 mar. 2018.

VALOR ONLINE. Sanepar adia oferta global de ações preferenciais. São Paulo, 2002 a. Disponível em: <http://www.valor.com.br/arquivo/283663/sanepar-adia-oferta-global-deacoes-preferenciais $>$. Acesso em: 29 mar. 2018.

XAVIER, P. H. Acordo de acionistas e o princípio da indisponibilidade. Curitiba, 2002. Disponível em: <http://www.tribunapr.com.br/noticias/acordo-de-acionistas-e-o-principio-daindisponibilidade/>. Acesso em: 29 mar. 2018.

Recebido em: 30 maio 2019.

Aceito em: 10 jun. 2019. 